\title{
PREVENTING MEDICATION ERROR BASED ON KNOWLEDGE MANAGEMENT AGAINST ADVERSE EVENT
}

\author{
Apriyani Puji Hastuti*, Nursalam**, Mira Triharini** \\ *Nursing Study Program- Poltekkes RS dr Soepraoen Malang \\ **Nursing Faculty - Universitas Airlangga Surabaya \\ Email: ns.apriyani@gmail.com
}

\begin{abstract}
Introductions: Medication error is one of many types of errors that could decrease the quality and safety of healthcare. Increasing number of adverse events (AE) reflects the number of medication errors. This study aimed to develop a model of medication error prevention based on knowledge management. This model is expected to improve knowledge and skill of nurses to prevent medication error which is characterized by the decrease of adverse events (AE). Methods: This study consisted of two stages. The first stage of research was an explanative survey using cross-sectional approach involving 15 respondents selected by purposive sampling. The second stage was a pre-test experiment involving 29 respondents selected with cluster sampling. Partial Leas square (PLS) was used to examine the factors affecting medication error prevention model while the Wilcoxon Signed Rank Test was used to test the effect of medication error prevention model against adverse events (AE). Results: Individual factors (path coefficient $12: 56, t=4,761$ ) play an important role in nurse behavioral changes about medication error prevention based in knowledge management, organizational factor (path coefficient $=0276, t=2.504$ ) play an important role in nurse behavioral changes about medication error prevention based on knowledge management. Work characteristic factor (path coefficient $=0309, \mathrm{t}=1.98$ ) play an important role in nurse behavioral changes about medication error prevention based on knowledge management. The medication error prevention model based on knowledge management was also significantly decreased adverse event $(p=0.000, \alpha<0.05)$. Discussion: Factors of individuals, organizations and work characteristics were important in the development of medication error prevention models based on knowledge management.
\end{abstract}

Keywords: Medication error, knowledge management, adverse events (AE)

\section{INTRODUCTION}

Medication error is one type of error that gets the most attention effort to improve the quality and safety of healthcare because it can increase the cost of health care in large numbers. Some of the most common medication errors are misconduct, incorrect dosages, and incorrect intervals (FM Hurtsey, 2007). Nurses and other health professionals involved in the Management and Use of Drugs (Medication Management and Use/MMU) have a responsibility to create an environment and working practices that prioritize the patient safety. Medication error is deemed to occur if drug chart of patients showed any of the following: illegible handwriting, medication name and dosage error, medication admission, and access, discharge medication (Wei, Shrestha, Williamson, \& Morgan, 2011). Efforts should be made to improve safety in drug delivery include national efforts, education, and training for nurses and system changing (Roterman, 2014).

Studies related to the causes of medication errors have been done and the result shows that lack of knowledge dissemination, especially $22 \%$ of the doctors who constitute the cause of error, insufficient information about the patient as well as laboratory data test and possibly the cause of dosing error is $10 \%$ does not obey the standard operational procedure and forgot $9 \%$ as the cause of medication errors. Another causes related to misreading the prescription, wrong interpretation and abbreviations commands of prescription, misunderstanding verbal commands, confusing the nomenclature of labeling and packaging, wrong storage of medicine, standard and distribution problem, error delivery when purchasing and using drug for example chemotherapy drug infusion, disruption of tension and work environment; unknowledgeable patients (Roterman, 2014).

Based on the report of Hospital Safety Committee in 2010, incidences of medication errors during January-April 2010 reached $16.67 \%$. Nationally, $36 \%$ of medication errors occur in the administration phase (Paparella, 2011). In the period of May until August 2010, there was $11.1 \%$ incidence of medication errors or third ranks incident after incident errors in clinical procedure and patient falls. The high incidence of medication errors due to patient safety needs serious attention from health professionals, especially nurses who play a role in the administration of drugs 
(medical administration). Medication errors can cause serious adverse effect and potentially to evoke the fatal risk of the disease (Perwitasari, Abror, \& Wahyuningsih, 2010).

A preliminary study conducted on April 16, 2016, at RSUI Malang found that the number of patients with uncontrollable drug reactions and the medication error in January December 2015 were 30 cases with the majority of patients are allergic to analgesic, antipyretic and antibiotic drugs. Quality Improvement of Patient Safety Team of RSUI Malang has conducted risk grading including medium risk, simple investigation to the incident at the longest two weeks and the leadership commitment to manage the risk in preventing medication error. From the observation, it is found that there were still errors in drug injection and delivery medication schedule. While on the documentation aspect, the nurse only wrote down the activity of medication that has been done without a report or wrote the patient's response to the medication that has been given.

Medications are classified based on potential risk for medication errors/adverse drug events: high risk, moderate risk and low risk (Swinkey \& Manthey, 2001; Zafar, 2007). Adverse event occurs due to the negligence of the nurse and medication errors. This fault happens because of high workload and a high number of inpatient. Knowledge management in the institution to organize knowledge and facilitate employee to access information so that employees are informed and can apply it and affect employee performance. Most knowledge can be obtained from some factors that include education, experience themselves or other people, the mass media and the environment. Domain knowledge is very important for the formation of a person's behavior (W. Maalej, 2013). To prevent adverse event cause of medication error, The supportive strategies for improving perception for the use of IT-based systems would add to system construction, and positive error management climate would be more easily promoted (Kim, 2012)

Knowledge management approach will be used in the prevention of medication errors (Gasik, 2011). Knowledge management according to Gasik (2011) is a development of the concept of knowledge management by Nonaka and Takeuchi (1995). Knowledge management has 7 stage, there are identification; knowledge acquisition, knowledge creation, knowledge application, knowledge transfer, knowledge sharing, knowledge documentation. The advantages of this model are on the data processed through collecting, classifying and grouping, so that it changes the shape and nature of their intended use, interpret the data, data storage, data delivery to the user, and its usefulness in supporting the interests of the organization. This model is based on the traditional model of quality and excellence so that there is a very strong relationship between knowledge management processes and organization with the expected results. The role of knowledge management as a whole is positioned as a tool that helps organizations to achieve the goal. Knowledge management approach is the concept of managing knowledge that has been established to be applied to practice by the knowledge that has been gained and reflected in the performance of a nurse so that unexpected events related to the administration of drugs can be minimized.

\section{METHODS}

The first stage was explanative survey using cross-sectional and second stage was pre-experiment, the purpose was to prepare a model of medication error prevention-based on knowledge management model including to raise strategic issues of nurses. Respondents in the first stage are 31 nurses in the ICU, Firdaus and Mina rooms which selected by purposive sampling. The purpose of the second stage was a trial of medication error prevention-based model of knowledge management against unexpected events. Data were collected using questionnaires, observation and analyzed by using Partial Least Square (PLS). PLS results and strategic issues then lifted into the Focus Group Discussion (FGD) with the aim to develop a medication error prevention modulebased knowledge management. Participants of FGD were 15 respondents consists of team Patient Safety, Nurse Unit Manager (NUM), the nursing committee selected by purposive sampling. Nurses implemented a module that resulted by FGD in the second stage of research. Respondents of the second stage are 29 in room Safa - Marwah, Mumtazah and Arofah which collected by using cluster sampling. Respondents of the second phase were observed in implementing the module of 
Preventing Medication Error Based on Knowledge Management (Apriyani Puji H. et.al)

medication error prevention - based on and the data were analyzed using the Wilcoxon Signed Rank Test

\section{RESULTS}

The results of the first stage described the causes of medication error (individual factors, organizational factors, job characteristic) and prevention of medication error based on knowledge knowledge management to the adverse event management (assessment, planning, implementation, evaluation). The distribution of respondents' answers can be seen in table 1 and table 2.

Table 1 shows the cause of medication error including individual factors, organizational factors, and respondent's work characteristic.

Table 1. Distribution Causes of Medication Error

\begin{tabular}{|c|c|c|c|c|c|}
\hline No & Indicator & $\begin{array}{l}\text { Good } \\
\text { f }(\%) \\
\end{array}$ & $\begin{array}{c}\text { Moderate } \\
\text { f }(\%)\end{array}$ & $\begin{array}{r}\text { Low } \\
\text { f }(\%) \\
\end{array}$ & $\begin{array}{l}\text { Total } \\
\text { f }(\%) \\
\end{array}$ \\
\hline \multicolumn{6}{|c|}{ Individual Factors } \\
\hline 1 & Knowledge & 0 & $24(77 \%)$ & $7(23 \%)$ & $31(100 \%)$ \\
\hline 2 & Ability and skill & 0 & $31(100 \%)$ & 0 & $31(100 \%)$ \\
\hline 3 & Psychological & 0 & $30(97 \%)$ & $1(3 \%)$ & $31(100 \%)$ \\
\hline \multicolumn{6}{|c|}{ Organizational Factors } \\
\hline 1 & $\begin{array}{l}\text { Organizational } \\
\text { Comitment }\end{array}$ & $1(3)$ & $30(97)$ & 0 & $31100 \%)$ \\
\hline 2 & $\begin{array}{l}\text { Structur \& } \\
\text { Organizational culture }\end{array}$ & 0 & $27(87 \%)$ & $4(13 \%)$ & $31(100 \%)$ \\
\hline \multicolumn{6}{|c|}{ Respondent's Work Characteristics } \\
\hline 1 & Objective performance & 0 & $31(100 \%)$ & 0 & $31(100 \%)$ \\
\hline 2 & Feedback & $7(23 \%)$ & $24(77 \%)$ & 0 & $31(100 \%)$ \\
\hline
\end{tabular}

Tabel 2. Prevention of medication error based on knowledge management

\begin{tabular}{|c|c|c|c|c|}
\hline \multirow[b]{2}{*}{ Indicator } & \multicolumn{3}{|c|}{ Category } & \multirow[b]{2}{*}{ Total } \\
\hline & $\begin{array}{l}\text { Good } \\
\text { f (\%) }\end{array}$ & $\begin{array}{c}\text { Moderate } \\
\text { f (\%) }\end{array}$ & $\begin{array}{l}\text { Low } \\
\text { f (\%) }\end{array}$ & \\
\hline \multicolumn{5}{|l|}{ Assessment } \\
\hline Knowledge identification & - & $23(74 \%)$ & $8(26 \%)$ & $31(100 \%)$ \\
\hline Knowledge application & $1(3 \%)$ & $26(84 \%)$ & $4(13 \%)$ & $31(100 \%)$ \\
\hline Knowledge Sharing and Transfer & $2(6 \%)$ & $17(55 \%)$ & $12(39 \%)$ & $31(100 \%)$ \\
\hline Knowledge repository & 0 & $27(87 \%)$ & $4(13 \%)$ & $31(100 \%)$ \\
\hline \multicolumn{5}{|l|}{ Intervention } \\
\hline Knowledge identification & - & $25(81 \%)$ & $6(19 \%)$ & $31(100 \%)$ \\
\hline Knowledge application & - & $29(94 \%)$ & $2(6 \%)$ & $31(100 \%)$ \\
\hline Knowledge Sharing and Transfer & $5(16 \%)$ & $21(68 \%)$ & $5(16 \%)$ & $31(100 \%)$ \\
\hline Knowledge repository & $1(3 \%)$ & $22(71 \%)$ & $8(26 \%)$ & $31(100 \%)$ \\
\hline \multicolumn{5}{|l|}{ Implementation } \\
\hline Knowledge identification & - & $30(97 \%)$ & $1(3 \%)$ & $31(100 \%)$ \\
\hline Knowledge application & - & $31(100 \%)$ & - & $31(100 \%)$ \\
\hline Knowledge Sharing and Transfer & $2(6 \%)$ & $26(84 \%)$ & $3(10 \%)$ & $31(100 \%)$ \\
\hline Knowledge repository & $2(6 \%)$ & $21(68 \%)$ & $8(26 \%)$ & $31(100 \%)$ \\
\hline \multicolumn{5}{|l|}{ Evaluation } \\
\hline Knowledge identification & $2(6 \%)$ & $21(68 \%)$ & $8(26 \%)$ & $31(100 \%)$ \\
\hline Knowledge application & - & $25(81 \%)$ & $6(19 \%)$ & $31(100 \%)$ \\
\hline Knowledge Sharing and Transfer & $2(6 \%)$ & $20(65 \%)$ & $9(29 \%)$ & $31(100 \%)$ \\
\hline Knowledge repository & $4(13 \%)$ & $22(71 \%)$ & $5(16 \%)$ & $31(100 \%)$ \\
\hline
\end{tabular}


For individual factors, mostly the knowledge of respondents in preventing medication error is in the moderate category (77\%). All respondents $(100 \%)$ have the ability and skill in the moderate category, and most respondents have psychological factor in the moderate category (97\%) for organizational factors, organizational commitment in preventing medication error mostly in sufficient category $(97 \%)$ and organizational structure and culture mostly in enough category (87\%). For respondent's work characteristics, the objective performance of all respondents in sufficient category are (100\%), and feedback from the leadership in the sufficient category are 24 people $(77 \%)$.

As seen in Table 2, in the assessment phase, 23 people (74\%) has moderate knowledge identification, 26 people $(84 \%)$ has moderate knowledge application, 17 people $(55 \%)$ has moderate knowledge sharing, and transfer and 27 people $(87 \%)$ has moderate knowledge repository. In the planning stage, the majority of respondents has moderate knowledge identification (25 people), moderate knowledge application (29 people), moderate knowledge sharing and transfer (21 people) and moderate knowledge repository (22 people). In the implementation phase the majority of respondents to the knowledge identification quite as many as 30 people (97\%), knowledge application as many as 31 people (100\%), knowledge sharing and transfer as many as 26 people (84\%) and knowledge repository as many as 21 people $(68 \%)$. In the evaluation phase the majority of respondents to the knowledge identification as many as 21 people (68\%), knowledge application as many as 25 people $(81 \%)$, knowledge sharing and transfer as many as 20 people $(65 \%)$ and knowledge repository as many as 22 people (71\%). Observation result of 31 nurses from three rooms ICU, Mina, and VIP Eden who implement drug administration to patients through a variety of routes showed that adverse event is still happening as much as $1.5 \%$

\section{Model Development of Prevention Medication Error Based on Knowledge Management}

The results of the evaluation outer convergent value model validity can be seen in the following figures and tables. Based on picture 1 , it can be seen that all the indicators declared invalid where the value of outer loading by the expected criteria is above 0.5 . This shows that the whole indicator in the structural are valid.

Results Composite reliability to test the value of reliability indicators in this study can be seen in Table 3 .

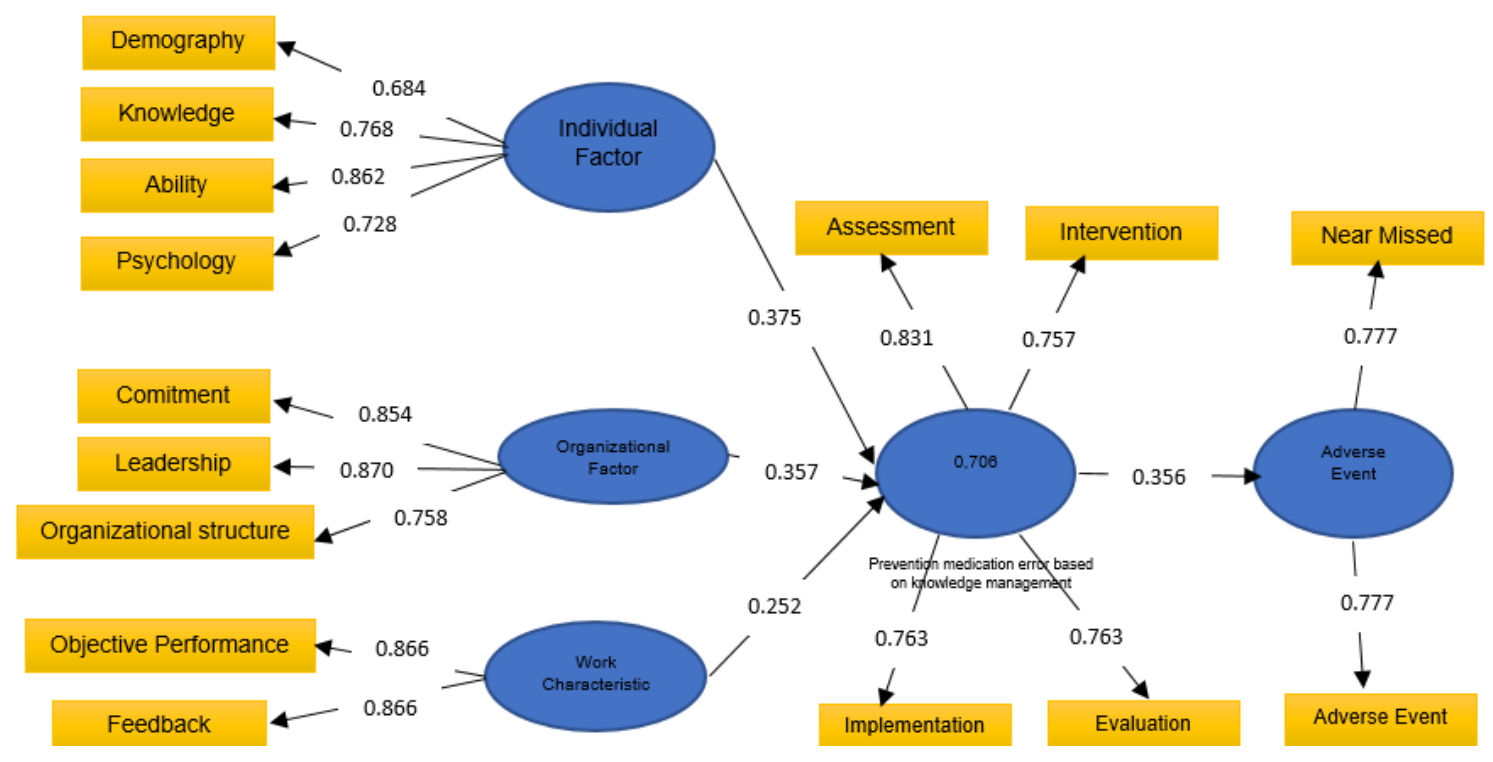

Picture 1 Outer loading Value on Prevention medication error model based on Knowledge Management 
Table 3. Results of Convergent Validity of the Prevention medication error model based on Knowledge Management

\begin{tabular}{llccc}
\hline No & \multicolumn{1}{c}{ Variable } & $\begin{array}{c}\text { Concronbach } \\
\text { Alpha }\end{array}$ & Composite Reliability & Note \\
\hline 1 & Individual factor & 0.733 & 0.834 & Valid \\
2 & Organizational factor & 0.769 & 0.867 & Valid \\
3 & Work characteristic & 0.668 & 0.858 & Valid \\
4 & $\begin{array}{l}\text { Prevention medication error } \\
\text { based on knowledge } \\
\text { management }\end{array}$ & 0.777 & 0.857 & Valid \\
\hline
\end{tabular}

Table 4. Statistical result of several variables that potentially prevent medication errors

\begin{tabular}{|c|c|c|c|}
\hline No & Variable & Result & Note \\
\hline 1 & Individual factor & $\begin{array}{l}\text { Path coefficient }=0.560 \\
\text { Standard deviation }=0,120 \\
\text { T statistic }=4,671\end{array}$ & Significant \\
\hline 2 & Organizational factor & $\begin{array}{l}\text { Path coefficient }=0,276 \\
\text { Standard deviation }=0,110 \\
\text { T statistic }=2,504\end{array}$ & Significant \\
\hline 3 & Work characteristic factor & $\begin{array}{l}\text { Path coefficient }=0,309 \\
\text { Standard deviation }=0,155 \\
\text { T statistic }=1,988\end{array}$ & Significant \\
\hline 4 & $\begin{array}{l}\text { Prevention medication error } \\
\text { based on knowledge } \\
\text { management }\end{array}$ & $\begin{array}{l}\text { Path Coefficient }=-0,486 \\
\text { Standard deviation }=0,063 \\
\text { T Statistic }=7,704\end{array}$ & Significant \\
\hline
\end{tabular}

The value of each variable composite reliability study showed a value of $>0.7$. Cronbach alpha value of each variable also showed a value of $>0.6$. It can be concluded that each variable has met reliability test.

These results indicate that there is a significant relationship between the variables individual, organization, and work towards the prevention of medication errors characteristicbased on knowledge management. There is a significant relationship between medication error prevention - based on knowledge management against the adverse event. The negative sign of the coefficient indicates the inversely proportional relationship means that the higher prevention medication error factorbased on knowledge management will decrease the incidence rate of an adverse event.

Recommendation of Focus Group Discussion (FGD) for module development in the prevention of medication error based on knowledge management against adverse event

1. Socialize about the adverse event and near missed to the nurses and allowed nurses to report to the Nurse Unit Manager and documented in patient safety report.

2. Patient safety report should regularly be reported to the patient safety team every week so that the risks can be found and prevention can be done immediately.

3. Socialize related to principles of correct drug administration and completeness of drug delivery instrument documentation sheet

4. Change the time of drug administration if the set time is still not applicable; give the autonomy to the each room related the drug administration so that the effectiveness of the drug is also noteworthy. Time of drug administration implemented 10.00-18.0002:00 hours

5. Documenting drug administration should be relevant to what is done by each nurse.

6. There is a reward for the room which carries out regular reporting of patient safety incidents and for the room with the most minimally incident related patient safety.

7. Sustainability and innovation in the prevention of medication errors should be 
considered to be applied continuously and improve patient safety.

\section{Phase 2}

The trial of the model conducted from May 8, 2016. The pre-test conducted in 10-day by observation of nurses behavior in preventing medication errors and unexpected events. Firstly, the module is given to nurses in Arofah Safa and Marwah and researcher explain about the module. Researcher accompanied the nurse in administering the drug for two weeks in the morning shift. After two weeks nurses perform independently until ten days and researcher observe it as a posttest.

The results of pre-test and post-test of implementation of the application of medication error prevention module-based on knowledge management can be seen in Table 5 .

Table 5. Results of Implementation of Medication Error Prevention-Based on Knowledge Management against adverse event

\begin{tabular}{|c|c|c|c|c|c|c|}
\hline \multirow{2}{*}{$\begin{array}{c}\text { Prevention medication } \\
\text { error based on knowledge } \\
\text { management }\end{array}$} & \multicolumn{3}{|c|}{ Pre } & \multicolumn{3}{|c|}{ Post } \\
\hline & Good & enough & less & Good & Enough & less \\
\hline \multicolumn{7}{|l|}{ Assessment } \\
\hline Knowledge identification & & & $29(100 \%)$ & $4(14 \%)$ & $25(86 \%)$ & 0 \\
\hline Knowledge application & $5(17 \%)$ & $22(76 \%)$ & $2(7 \%)$ & $14(48 \%)$ & $15(52 \%)$ & 0 \\
\hline $\begin{array}{l}\text { Knowledge Sharing and } \\
\text { Transfer }\end{array}$ & $2(7 \%)$ & $24(83 \%)$ & $3(10 \%)$ & $9(31 \%)$ & $20(69 \%)$ & 0 \\
\hline Knowledge repository & $5(17 \%)$ & $22(76 \%)$ & $2(7 \%)$ & $13(45 \%)$ & $16(55 \%)$ & 0 \\
\hline \multicolumn{7}{|l|}{ Intervention } \\
\hline Knowledge identification & 0 & $20(69 \%)$ & $9(31 \%)$ & $5(17 \%)$ & $24(83 \%)$ & 0 \\
\hline Knowledge application & $7(24 \%)$ & $22(76 \%)$ & 0 & $14(48 \%)$ & $15(52 \%)$ & 0 \\
\hline $\begin{array}{l}\text { Knowledge Sharing and } \\
\text { Transfer }\end{array}$ & $6(21 \%)$ & $21(72 \%)$ & $2(7 \%)$ & $7(24 \%)$ & $22(76 \%)$ & 0 \\
\hline Knowledge repository & $5(17 \%)$ & $18(62 \%)$ & $6(21 \%)$ & $7(24 \%)$ & $22(76 \%)$ & 0 \\
\hline \multicolumn{7}{|l|}{ Implementation } \\
\hline Knowledge identification & $17(59 \%)$ & $12(41 \%)$ & 0 & $18(62 \%)$ & $11(38 \%)$ & 0 \\
\hline Knowledge application & $6(21 \%)$ & $23(79 \%)$ & $2(7 \%)$ & $28(97 \%)$ & $1(3 \%)$ & 0 \\
\hline $\begin{array}{l}\text { Knowledge Sharing and } \\
\text { Transfer }\end{array}$ & $5(17 \%)$ & $22(76 \%)$ & $2(7 \%)$ & $6(21 \%)$ & $23(79 \%)$ & 0 \\
\hline Knowledge repository & $12(41 \%)$ & $17(59 \%)$ & 0 & $14(48 \%)$ & $15(52 \%)$ & 0 \\
\hline \multicolumn{7}{|l|}{ Evaluation } \\
\hline Knowledge identification & 0 & 0 & $29(100 \%)$ & $5(17 \%)$ & $24(83 \%)$ & 0 \\
\hline Knowledge application & 0 & 0 & $29(100 \%)$ & $8(28 \%)$ & $21(72 \%)$ & 0 \\
\hline $\begin{array}{l}\text { Knowledge Sharing and } \\
\text { Transfer }\end{array}$ & 0 & $1(3 \%)$ & $28(97 \%)$ & $10(34 \%)$ & $19(66 \%)$ & 0 \\
\hline Knowledge repository & 0 & 0 & $29(100 \%)$ & $10(34 \%)$ & $19(66 \%)$ & 0 \\
\hline
\end{tabular}

Table 6. Statistical analysis of pre and post intervention between adverse event and near missed

\begin{tabular}{cclc}
\hline & $\Delta-\mathbf{S D}$ & $\mathbf{Z}$ & \multicolumn{1}{c}{ Asymp. Sig (2-tailed) } \\
\hline Advers event & $0.15 \pm 0$ & 2.023 & 0.043 \\
\hline Near missed & $89.08 \pm 3.78$ & 4.703 & 0.000 \\
\hline Results of statistical analysis of the near & than the standard value of $\alpha=0.05$ which \\
missed by using Wilcoxon Signed Rank test & $\begin{array}{l}\text { indicates that the is an influence of } \\
\text { medication error prevention knowledge }\end{array}$
\end{tabular}


management based on the nearly missed incident. While the results of the statistical analysis of the adverse event by using Wilcoxon Signed Rank Test showed significance value $(p)=0.043$, less than the standard value of $\alpha=0.05$ which indicates that there is the influence of medication error prevention-based on knowledge management against the adverse event.

\section{DISCUSSION}

\section{Individual Factors Against the Prevention of Medication Error Based on Knowledge Management}

The results of PLS analysis obtained that the coefficient value of 0.56 lines and 4,671 t statistic $(t>1.96)$. It can be concluded that individual factors contribute to the adoption of knowledge management-based medication error and indirectly an attempt to reduce the adverse event. Components of the individual factors include knowledge, abilities, skills of nurses, and psychological. Mc. Closhey \& Mc. Cain (1988) research results which cited in Gillies (2004) stated that nurses who have higher education also have the ability to work better. Efforts to increase knowledge is an important thing especially in the context of patient safety. Human resource-limited knowledge was health services problem to unable manage service-oriented based on patient safety which is a required key for the sake of security created by the care given by health workers, including nurses.

In this case, the ability and skills of nurses related to the implementation of the drugs correct administration principles conducted by nurses include right patient, right drug, right indication, right dose, right route of administration, the correct time and the correct documentation.

Psychological factors include perception, motivation, attitude and willingness to learn. Perception in this case related to the satisfaction of nurses to the salary given by the health services. The motivation of nurse to maintain patient safety efforts and motivation of the leadership that made more development in work. The attitude and willingness to learn make nurses more responsible for their actions. Their high willingness to study of RSUI nurses thus requiring hospital organization active role as a media to conduct information and knowledge for nurses.

\section{Organization Factors Against the Prevention of Medication Error Based on Knowledge Management}

The study results, the analysis of PLS obtained coefficient $t$ statistic lines 0276 and $2504(t>1.96)$, these results suggest that there is significant influence between the variables of organizational factors on medication error prevention-based knowledge management. Organization factors have sub-variables included organizational commitment, leadership, structure, and culture of the organization.

The organization structure shows how a group designed, lines of communication and relationships of authority and decision-making (Marquis \& Huston, 2000). Organization commitment stated here include hospitals vision and mission suitability, reward and punishment, training and development. RSUI's Vision and the mission were appropriate, particularly related to Quality Improvement and Patient Safety. Reward and punishment imposed by the hospitals, especially in a room with a patient safety incident reporting implemented by regularly documented every week and every month. Currently, nurses in the hospitals are still got no reward and punishment in particular, but every month there is a favorite nurse election based on a poll of the patient. Training and development at RSUI were based on their regular schedule in the improvement of knowledge especially nurses with information in the form of inhouse training with the involvement of the expert of experts according to the field or socialization by peers who have been carrying out training of ex-house training.

Instruction model leadership is indicated by the high task and low relationship. RSUI leadership has contributed greatly to the compliance of nurses in implementing guidelines for prevention of medication errors. This is consistent with the theory that nurse manager has a very important role in implementing patient safety, especially the prevention of medication errors. In other research, any correlation between nurse's knowledge levels with right principle implementation of medication on injection action (Gede, Pratama, Prabowo, \& Rahil, n.d.)

The organization system in RSUI was well structured so that the chain of command and 
coordination lines between each field can be implemented quite well. Given the structure of a good organization can support nurse adherence in doing medication error prevention.

\section{Work characteristic Against the Prevention of Medication Error Based on Knowledge Management}

The results of PLS analysis obtained coefficient lines 0309 and t statistic is $1.98(t>$ 1.96). This showed that there is significant influence between variable factors, work characteristic against the prevention of medication errors based knowledge management. Further found also showed that the objective performance is a domain factor related to nursing compliance in applying the prevention of medication errors.

Robbin (2008) stated that a work characteristic is an approach to work that is specified in 5 dimensions of the core characteristics: skill variety, task identity, task significance, autonomy, and feedback.

In RSUI Malang district, job design delivered at the beginning of nurse orientation after they accepted as a nurse. Nurses are oriented about their responsibilities, rights, and duties as a nurse at the hospital. This activity is closely related to job performance, and supervision carried out by hospitals, but this activity still does not yet implemented optimally. Therefore, the hospital should perform evaluation and amelioration of performance and supervision.

\section{Implementation of Medication Error} Prevention - Based on Knowledge Management against Adverse Event

The trial model of knowledge-based prevention of medication errors management as an effort to decrease the adverse event of 4 modules that have been tested to decrease the adverse event. The significant difference is the inaccuracy of time and documentation, where nurses do not realize the impact that may arise in the administration of drugs that do not correspond with the timing so that the next shift could be faster or slower administer the drugs so it can influence the effectiveness of drug delivery.

Based on the overall hypothesis testing, it can be seen significant lines, models describing these results is the variable of individuals ability, organizations and work characteristic variable against the prevention of medication errors based knowledge management and indirectly to decrease the adverse event.

\section{CONCLUSIONS}

Individual factors (demographics data, level of knowledge, abilities, and skills, and psychological) significantly influence on the prevention of medication errors based on knowledge management. While organizational factors (organizational commitment, leadership, structure, and organizational culture) significantly affect the prevention of medication errors based on knowledge management. Job characteristic factors (objective performance and feedback) significantly influence the medication error prevention-based knowledge management.

Model of medication error preventionbased on knowledge management is influenced by individual factors, organization and work characteristic. Medication error preventionbased knowledge management can significantly reduce the unexpected incidence. Learning with knowledge management methods are used so that the nurse can learn about discussion, formulate, and decide on knowledge gained so can be easily applied to the ability of nurses in drug delivery.

To enhance the prevention of medication error, it needs to make a list of the order of nursing personnel who will participate in continuing education, training or seminars as a form of nursing staff's knowledge increase. Application of medication error prevention module-based on knowledge management can be performed on orientation activities at the first time of nurse work. Create pre-conference and post-conference activities routine at every turn shift as a medium to add information and knowledge for nurses. Create continue evaluation and supervision for nurses to conduct the safe administration of drugs and as an effort to improve the behavior of the nurses. Enable the nursing committee specifically to credentialing about the nurse actions. Initiate PMKP program proactively that spurred the realization of a work culture toward patient safety oriented. Hold a gradual guidance and training for nurses who still have less working period regarding its implementation about the hospital's patient safety. 


\section{REFERENCES}

FM Hurtsey, W.N, 2007, Inappropriate Prescribing in Older ED Population. AM J Emerg Med, 22-32

Gasik, S, 2011, A Model of Project Knowledge management, Project Management Journal, 42(3), 23-44.

Gede, I. D., Pratama, M., Prabowo, T., \& Rahil, N. H. (n.d.). The relation between nurse' s knowledge levels with right principle implementation of medication on injection action at rsud wates.

Gillies, 2004, Manajemen Keperawatan: Suatu Pendekatan Sistem, Edisi Kedua, Philadelphia, WB Saunders

Kim, M. S. (2012). Medication Error Management Climate and Perception for System Use according to Construction of Medication Error Prevention System. Journal of Korean Academy of Nursing, 42(4), 568. https://doi.org/10.4040/jkan.2012.42.4.56 8

Marquis \& Huston, 2010, Kepemimpinan dan Manajemen Keperawatan. Jakarta: EGC

Paparella, S. (2011). Is a back to basics approach to medication error reduction enough? Journal of Emergency Nursing. https://doi.org/10.1016/j.jen.2011.05.003

Perwitasari, D. A., Abror, J., \& Wahyuningsih, I. (2010). Medication Errors In Outpatients Of A Government Hospital In Yogyakarta Indonesia, 1(1), 8-10.
Robbins, 2008, Perilaku Organisasi Edisi Ke12, Jakarta, Salemba Empat

Roterman, I, 2014, Simulation in Medicine, Walter de Gruyter GmbH \& Co KG. Kualitatif, Kuantotatif dan $R \& D$. Bandung, Alfabeta.

Swinkey, N. J., \& Manthey, C. W. (2001). Medication error/adverse drug event (MEADE) classification. ASHP Midyear Clinical Meeting, 36, P-737D.

W. Maalej, A. T, 2013, Managing Requirements Knowledge. SpringerVerlag Berlin Heidelber.

Wei, S., Shrestha, R., Williamson, J., \& Morgan, C. (2011). Medication error prevention programme. Internal Medicine Journal.Conference: Royal Australasian College of Physicians Congress 2011 Darwin, NT Australia.Conference Start: 20110522 Conference End: 20110525.Conference Publication: (var.pagings).41 ()(Pp 45), 2011.Date of Publication: May 20. Retrieved from DO http://dx.doi.org/10.1111/j.14455994.2011.02494.x

Zafar, A. (2007). MEADERS: Medication Errors and Adverse Drug Event Reporting system. AMIA ... Annual Symposium Proceedings / AMIA Symposium. AMIA Symposium, 1167. Retrieved from http://www.ncbi.nlm.nih.gov/pubmed/18 694263 